\title{
INTERDISCIPLINARITY AS HEURISTIC RESOURCE FOR ENERGY MANAGEMENT
}

\author{
L. GITELMAN ${ }^{1}$, E. MAGARIL ${ }^{1} \&$ M. KHODOROVSKY ${ }^{1,2}$ \\ ${ }^{1}$ Ural Federal University, Russia. \\ ${ }^{2}$ SINARA Group, Russia.
}

\begin{abstract}
As high-tech industries continue to experience dynamic growth and problems of development in high-tech industries are getting increasingly complex, managers have to embrace the need for new competencies that match present-day challenges. This calls for a qualitative change in the architecture of education to bring it up to date with contemporary trends. Using cases from Russia, the paper aims to provide a groundwork for an interdisciplinary approach to building professional competencies in energy managers as a framework for forward-looking management of high-tech industries in a nonlinear environment. The authors identify factors that determine the new management imperative and set out methodological principles of developing a management culture. A model of professionalism in management is proposed that is the result of a complex interplay of interrelated competencies. The paper also explains the key features of an interdisciplinary training programme. To prove the research hypothesis, an analysis was conducted of empirical data from expert reviews by executives at Russian energy companies and leading academics.
\end{abstract}

Keywords: energy management, inderdisciplinarity, methodology culture, model of professionalism, professional competences, training programme.

\section{INTRODUCTION}

The novelty, scale, complexity and variety of problems that have to be addressed in the time of rapid change and uncertainty give rise to requirements that management can only meet through considerable changes in the content of professionalism and the system of keeping it on a par with the highly competitive market (Fig. 1). This imperative is determined by

- globalization and super-fast transfer of knowledge, technology, manpower and capital;

- expanding and deepening systemic ties between business and a range of the most complex technologies;

- an increasing importance to business of forward-looking solutions and, therefore, the relevance of prognostic and analytical functions;

- the constant application of new research-intensive management tools (risk-management, business models, intelligent decision support systems, etc.);

- the need for managers to constantly update their knowledge and, consequently, to keep their mind flexible and learn perpetually;

- the expansion of web-based teamwork involving experts from all over the globe.

\section{INTELLIGENT MANAGEMENT AS A JOB}

Managers face the need to master models for interpreting future uncertainties, the means of countering threats and taking advantage of opportunities. He or she has to be able to quickly select and modify their professional tools in line with new situations, circumstances and problems. This effectively means being able to create one's own methodology for solving this or that complex problem. This is what constitutes the core of modern management knowhow. 


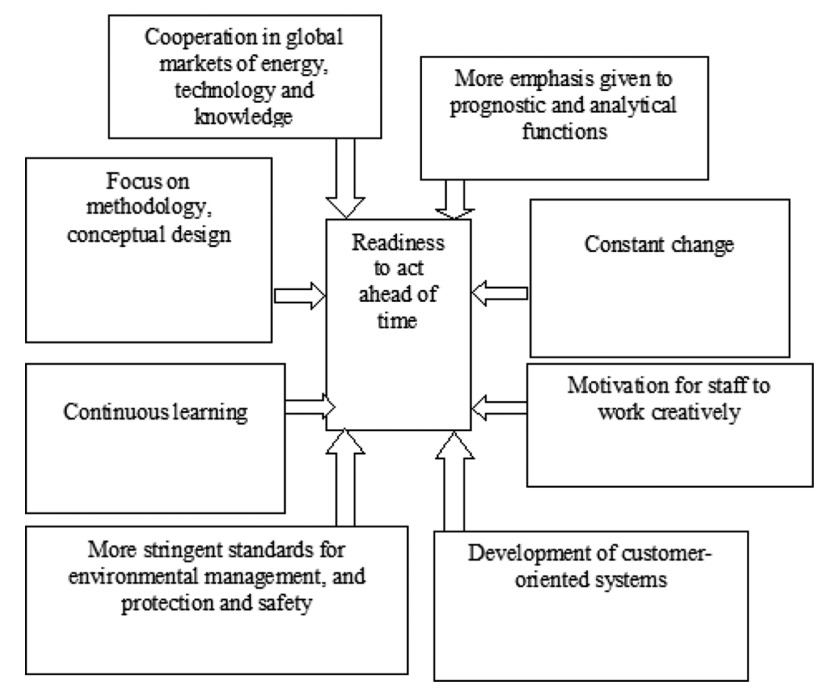

Figure 1: Factors that determine the new management imperative.

To have it, the manager should be able to build and constantly update his or her methodological culture.

Along with the above reasons that make management an ever more complex job, nationally distinct conditions, too, have their impact. For example, many developing countries are in need of overhauling their industry, urban infrastructure and logistics flows.

At the same time, they need to undergo a transition to a post-industrial economy based upon research-intensive high-tech industries, the service sector and appropriate infrastructure.

All of this will call for rapid qualitative changes in management culture, the content of management and decision-making algorithms. The changes are bound to take place against the background of management becoming generally more intelligent, which means stronger competence in solving complex tasks using modern scientific knowledge. The core point and the objective of increasing the intelligent capacity of management are to boost the predictive capability and adaptability of organizational systems to new conditions and enhance their readiness to act ahead of time. There is a broader demand for the competence to innovate (understanding of scientific and technological prospects of the industry, ability to organize the process of generating new ideas, integrating and transforming them into profit-making projects, to work in a team).

As a result, to be professional, a manager needs to be knowledgeable, to hold numerous competencies and personal qualities and always strive for self-improvement.

Naturally, management not only becomes industry-specific, but also there emerge new interdisciplinary areas of knowledge, along with the expansion of linkages across various areas of knowledge, experience and competencies.

\section{INTERDISCIPLINARY MANAGERS ARE NEEDED IN POWER ENGINEERING}

The current trend towards a massive overhaul of the most complex technology systems holds the key to a challenge to management education. The trend shows itself in all researchintensive industries (power engineering, nuclear power generation, aerospace engineering, 
aviation, radio electronics and IT, the petrochemical industry, advanced medical technology, etc.) in the following ways:

- the complexity of technology systems and the scale of innovation tasks grow;

- computer-integrated manufacturing (CIM) proliferates;

- online-based networking structures for international cooperation find wider application;

- security and environmental safety and protection systems.

Management is getting closely intertwined not only with technology and the profound knowledge of high-tech production processes, but also with economics, finance, investment, ecology and human resources.

Nurturing the appropriate competencies in managers requires a stronger emphasis on the interdisciplinary approach to training. By the interdisciplinary approach to training and research the authors mean the integration of knowledge acquired by studying individual disciplines and their interoperability at a new level of generalization that provides new conceptual and methodological opportunities for addressing complex present-day problems. Interdisciplinarity means intercommunication between two or more academic disciplines, areas of knowledge and expertise; it is an experience of interrelationships that can vary for a simple exchange of ideas to reciprocal integration of concepts, methodologies, terminology, learning and research arrangements [1].

It has to be noted that the terms multidisciplinary, interdisciplinary and transdisciplinary are used in the Russian and foreign literature on the subject, albeit in different contexts [2-5]. We would like to point out that interdisciplinarity is not so much about a combined study of problems from various subject fields as it is about cooperation, i.e. a synthesis of various areas of knowledge for the purpose of finding a new solution to a complex problem.

Interdisciplinarity brings into contact multiple disciplines, draws upon their theoretical frameworks, models, categories and concepts, setting in motion integratory processes, facilitating the interaction and enrichment of methods. This leads to the rethinking of traditional views, paradigms and concepts; reciprocal enrichment by using several paradigms at the same time for solving specific problems; new methods, means, conceptual tools and theoretical frameworks emerge; engagement and teamwork.

When teaching management, it is important to showcase the possibilities of the interdisciplinary methodology for comprehensive analysis of a situation, its heuristic effectiveness and collaborative arrangements.

It is also necessary to emphasize the need to possess engineering knowledge in specific industries and be aware of their systemic ties with the economy and finance. Of course, the amount of knowledge should correspondent to the manager's level of responsibility and job description. An entry-level production manager (foreman) must know thoroughly the production technology in his or her production unit or shop floor. Such jobs in high-tech industries are usually filled with engineering college graduates, whereas the CEO and top managers of a big corporation only need to have a general understanding of the technology and of how it influences business results. It is important to emphasize that without any knowledge of technology, the manager will be unable to master other competencies, even organizational and communicative ones because it will be impossible to have a shared vision and speak a common language with engineers.

Qualifications in economics and technology and the appropriate management culture are critical factors of interdisciplinarity: they bring together experts from different professional 


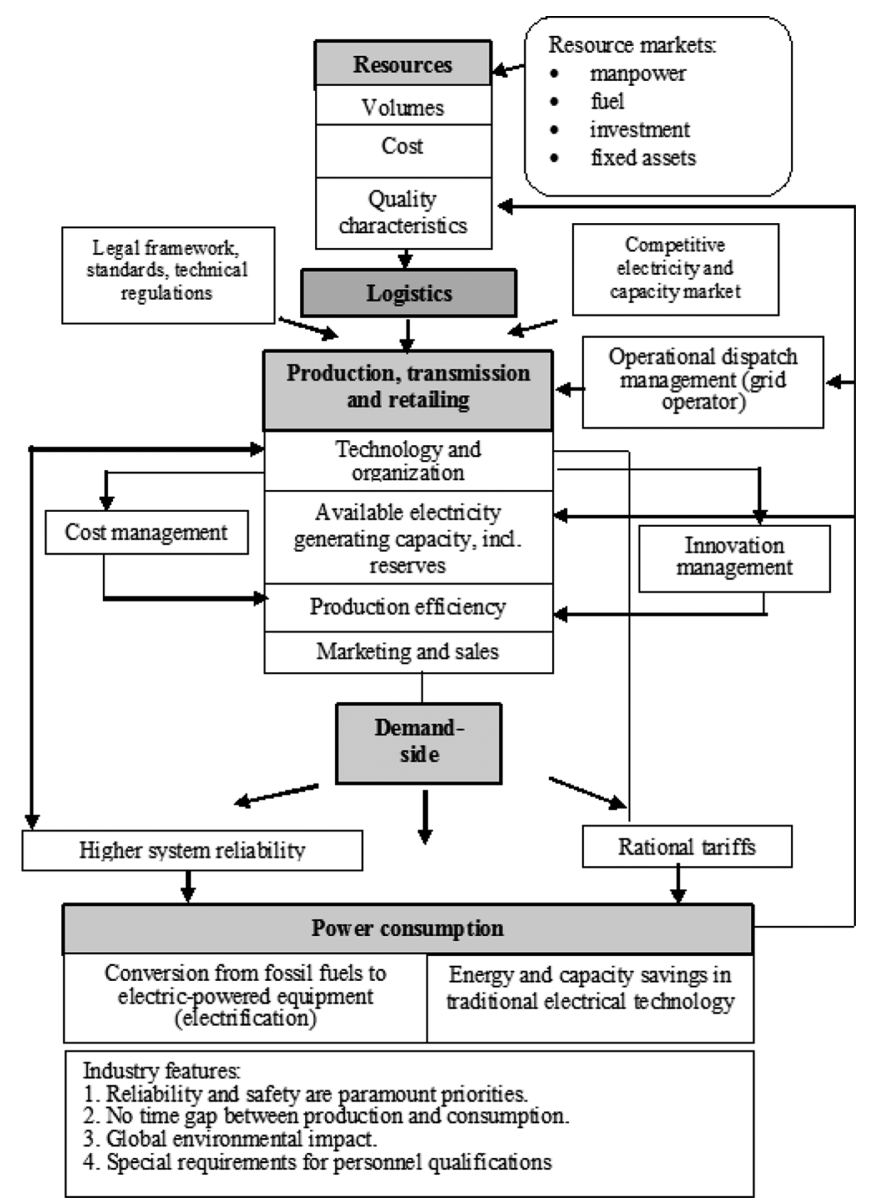

Figure 2: Functional linkages within energy management system (energy company).

fields and ensure rapport among them, which is particularly valuable when critical decisions need to be made. This makes interdisciplinary competences especially important in power engineering where the price of management mistakes is incomparably higher than in other industries [6].

The technological features of power engineering are clearly visible in all areas of the industry: production and financial planning, pricing, marketing, renovation of fixed assets, logistics, staff training and motivation (Fig. 2).

No management decision should contradict the technological platform of electricity generation and, above all, the principles of reliability, environmental friendliness and safety. It is, therefore, necessary to make sure that the technological, economic and finance sides work in sync; any lack of balance towards stronger regulation (standardization) will affect investors' interests, prompting them to withdraw from the industry. On the other hand, a lopsided focus on 'market values' might disrupt the orderliness of technological processes, lead to a pricing chaos and a technical collapse of the industry and its inability to fulfill its unique function of guaranteeing reliable power supply for the economy. Our observation of top managers, production managers, financial and economic managers shows that all of them experience the 
same qualification gap: they have little idea of the basic economics of power generation and, as a result, ignore the laws of technology and economics that govern power production.

This dictates the following methodological principles of building a management culture:

1. Technology decisions must be assessed in terms of their effectiveness as well as their financial, environmental, economic and social implications. The assessment should not boil down to the analysis of appropriate effectiveness indicators, but should also take into account their impact on the interests of all parties involved.

2. Organizational projects must be assessed for compliance with technological peculiarities and industrial regulation.

3. Technical infrastructure limitations of adjacent branches must be taken into consideration as additional characteristics of an economically efficient project. For example, enough attention is paid to the economic aspects of small-scale co-generation, whereas the technical side of it is often overlooked despite its critical role for making a decision about building a small-scale heat and power plant. When the generator runs in parallel with the grid, as compared to a standalone unit operating at full capacity, it is easier to ensure the quality of electricity, but at the same time the cogeneration unit will substantially increase the available short circuit current, thus making it necessary to perform costly renovations on the grid. The specifications of the grid that are usually related to parallel operation (requiring the installation of new protection relays) have to be taken into consideration when addressing the short circuit issue as meeting the specifications implies capital investment.

Environmental protection is a typical example of an overarching problem of technological development that calls for an interdisciplinary approach. It is quite possible to improve environmental conditions by implementing conservation practices that can have the same (or bigger) effect as a change in the production technology, but at a lesser cost. To make management decisions that take account of the economic efficiency and environmental effectiveness of conservation practices, it is necessary

- to justify the most rational conservation project;

- to investigate the environmental damage caused by the specific technological process;

- to identify factors affecting the size and structure of the negative and positive impacts of the chosen conservation project; and

- to assess its economic efficiency and environmental effectiveness.

The listed tasks can only be solved by using vast knowledge from many related fields and are beyond the reach of domain-specific experts.

The key principles of assessing the economic efficiency and environmental effectiveness of conservation projects can be summarized as follows:

1. Use 'cost-benefit' analysis. When evaluating the efficiency of conservation practices, compare their benefits and the costs associated with implementing the practices.

2. Use the integral approach. This means taking into account the entirety of all benefits and negative effects of conservation practices. The costs and benefits have economic and environmental components that are equally significant, which makes it possible to assign an economic value to the environmental ones. 


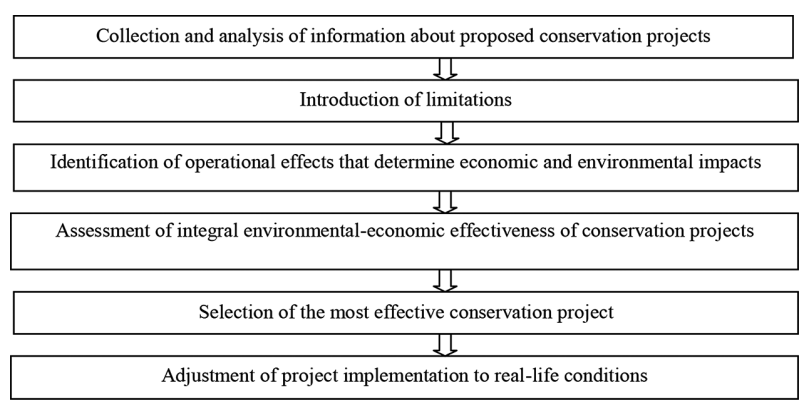

Figure 3: Scheme for assessing the economic efficiency and environmental effectiveness of conservation projects.

3. Consider the chance of non-occurrence of potential effects, both positive and negative ones, of conservation practices. This makes it essential to identify the operational effects of implementing a conservation project that determine the economic and environmental consequences $[7,8]$.

Figure 3 illustrates a scheme for assessing the economic efficiency and environmental effectiveness of conservation projects.

Consequently, to make management decisions when planning a conservation project, the manager must possess profound technical and economic expertise, the absence of which will make it impossible to identify operational effects. He or she should also have a set of competencies in various domains (finance, economics, management and ecology) that are best fostered through deepening the interdisciplinary approach to training.

\section{FOCUS OF NEW MANAGEMENT PROFESSIONALISM PARADIGM}

When making decisions and managing their staff, managers have to have knowledge from various subject fields and occupations: production, technology, the psychology of management and interpersonal relationships, economics and business finance, environmental economics and environmental protection, law, etc. In fact, management is related to many of them at the same time. The model of professionalism in management is, therefore, an interdisciplinary combination of interdependent competencies.

Traditionally, would-be managers acquire the necessary knowledge while studying individual disciplines at university, as well as by 'trial and error' during their actual work or further learning. All too often university degree programmes fail to mix individual courses within the logic of practical task solving, or to single out interdisciplinary aspects and interpret them through hands-on experience, that is, to arrange them into a whole 'picture' and to nurture the ability to combine and apply knowledge from various domains.

Consequently, the disciplinary-based approach to curriculum raises real barriers to planning effective management training: it prevents the creation of a holistic vision of management as a science and the development of a systemic management mindset. It also makes the processes of learning too theoretical.

Nowadays, when the ability to quickly respond to a changing situation, to understand it and interpret tasks in line with circumstances becomes a key element of professionalism, it is the interdisciplinary approach and its heuristic effects that enable one to quickly make decisions and implement them (Table 1). One can confidently expect the interdisciplinarity trend to grow as new complex tasks keep emerging and knowledge becomes increasingly inte- 
Table 1: Implementation of interdisciplinary approach in management training.

\begin{tabular}{|c|c|c|}
\hline People in training & Training goals & Tools for mastering interdisciplinarity \\
\hline $\begin{array}{l}\text { Management } \\
\text { students }\end{array}$ & $\begin{array}{l}\text { To acquire basic knowledge } \\
\text { and to learn to use it for } \\
\text { routine tasks and out-of-the- } \\
\text { ordinary situations }\end{array}$ & $\begin{array}{l}\text { Analysis of cases that demonstrate the } \\
\text { complexity of managerial work } \\
\text { Preparation of summary reports using } \\
\text { information from various domains } \\
\text { Development of systemic thinking } \\
\text { Conceptual design } \\
\text { Team projects }\end{array}$ \\
\hline $\begin{array}{l}\text { Entry level and } \\
\text { middle managers }\end{array}$ & $\begin{array}{l}\text { To solve routine tasks that fit } \\
\text { their level } \\
\text { To be able to analyse } \\
\text { problem situations, define } \\
\text { and solve problems } \\
\text { To have a value creation } \\
\text { mindset }\end{array}$ & $\begin{array}{l}\text { Demonstration of the multifaceted } \\
\text { and overarching nature of managerial } \\
\text { knowledge (for engineering graduates) } \\
\text { Training in best practices through case } \\
\text { studies } \\
\text { Business games, strategy sessions and } \\
\text { team work }\end{array}$ \\
\hline Top managers & $\begin{array}{l}\text { To be able to combine } \\
\text { economic, production, } \\
\text { environmental and political } \\
\text { goals } \\
\text { To be able to solve complex } \\
\text { tasks that spread beyond a } \\
\text { single field of knowledge } \\
\text { To develop the abilities to } \\
\text { quickly adjust vision and } \\
\text { priorities } \\
\text { To be able to create teams } \\
\text { To set up large-scale } \\
\text { transformations }\end{array}$ & $\begin{array}{l}\text { Building a holistic vision } \\
\text { Methods of generating news business } \\
\text { ideas } \\
\text { Emergency response } \\
\text { Conceptual design } \\
\text { Business games, strategy sessions and } \\
\text { team work } \\
\text { Fostering professional reflection }\end{array}$ \\
\hline
\end{tabular}

grated and differentiated. It is already quite common today for business to engage in overarching research, to deal with borderline cases, to employ innovation teams of experts from various domains and professional backgrounds, to arrange strategy sessions and business games aimed at solving present-day problems.

The empirical data of the research (Fig. 4) highlight elements of growing importance for management in electrical power systems. For example, the experts believe it is necessary to pay due attention to the issues of engineering, technology, scientific and technical prospects and interdisciplinary ties within the industry, readiness to innovation, training in self-learning and self-development methods. The survey involved 460 persons, including 30 university professors, 80 top managers and 350 middle managers working for energy companies in various regions of Russia.

The conclusion about the importance of interdisciplinary issues in management education is backed by the results of a survey with the participation of 200 middle managers from 12 major Russian companies (Fig. 5). 


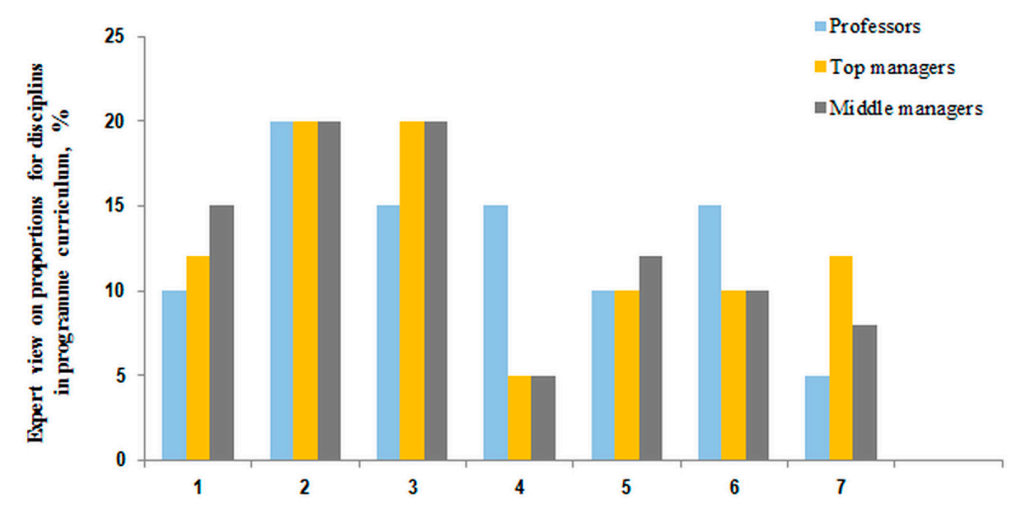

Figure 4: Proportions of disciplines in master's degree programme in power engineering: 1 - knowledge of global context and interdisciplinary ties between power engineering and environmental safety systems; 2 - management (forecasting methods and foresight; smart systems and decision support systems for abnormal situations; conceptual design, strategic behaviour amid uncertainty; leadership, team building); 3 - economics (markets, asset management, highly professional service; intellectual capital, business value); 4 - methods and techniques for analysis, research, consulting and teaching; 5 - self-learning and self-development methods; 6 - readiness to innovate; 7 - foreign economic activity.

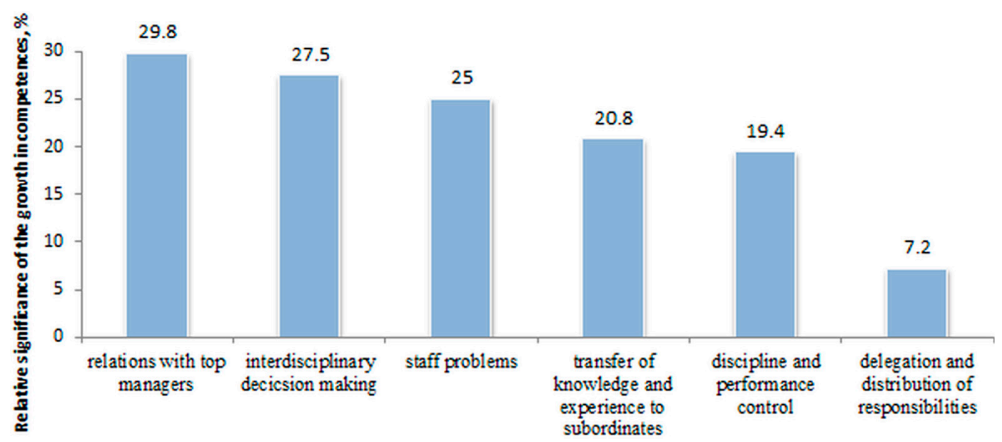

Figure 5: Job functions for which energy managers need to build competencies.

Developing a practice-based interdisciplinary educational programme is fundamentally different from creating a traditional course in a specific discipline:

1. An interdisciplinary programme is always unique: it reflects the specific nature of the energy company's operation and its managers' work-related tasks. Such a programme is based upon the analysis of the company's strategic goals and objectives and issues that impede their implementation, challenges faced by managers, organizational and production characteristics of the company.

2. An interdisciplinary programme is always concept-based: it is driven by ideas that open new opportunities for solving tasks faced by the management. Without an underlying idea, it would be a standard set of special courses and themes borrowed from authoritative textbooks. 
3. Developing and delivering an interdisciplinary educational programme requires experts with different backgrounds and competencies. That is why it is interdisciplinary content that people planning a company's strategy, a new business and other innovative projects deal with.

\section{CONCLUSIONS}

Today energy managers must act ahead of time, which means being able to adapt to new situations faster than your competitors do, to forecast how the situation will unfold and use unconventional tools for solving complex problems. This is a brand new type of management.

A manager can only act ahead if he or she possesses competencies that make it possible to overcome the barriers of a complex and non-linear environment. Among the competencies, the prime one is the ability to predict future technological breakthroughs in power generation as well as in energy consumer relations and smart systems ensuring security, reliability and environmental safety.

The challenge of acting ahead of time calls for a transition to a new paradigm of management education and a model for competence development that lean towards the interdisciplinary approach, systemic integration of various subject fields, monitoring of technological advances in the industry and learning to quickly master the newest tools for decision making and implementation.

\section{REFERENCES}

[1] Berger, G., Opinions and facts. Interdisciplinarity: Problems of Teaching and Research in Universities, eds. L. Apostel et al., OECD: Paris, pp. 23-75, 1972.

[2] Somerville, M. \& Rapport, D., Transdisciplinarity: ReCreating Integrated Knowledge. EOLSS Publishers: Oxford, UK, 2002.

[3] Kiyashchenko, L.P., Opyt filosofii transdistsiplinarnosti: (kazus 'bioetika') [in Russian]. Voprosy filosofii [Problems of Philosophy], 8, pp. 105-117, 2005.

[4] Augsburg, T., Becoming transdisciplinary: the emergence of the transdisciplinary individual. World Futures, 70(3-4), pp. 233-247, 2014. doi: http://dx.doi.org/10.1080/ 02604027.2014.934639

[5] Bushkovskaia, E.A., Fenomen mezhdistsiplinarnosti v zarubezhnykh issledovaniiakh [in Russian]. Bulletin of Tomsk State University, 330, pp. 152-155, 2010.

[6] Gitelman L.D. \& Ratnikov B.E., Ekonomika i biznes v elektroenergetike [in Russian], Ekonomika: Moscow, 2013.

[7] Magaril, E.R., Bereziuk, M.V. \& Rukavishnikova, I.V., Ekonomika prirodopol'zovaniia. Mezhdistsiplinarnyi podkhod [in Russian], KDU: Moscow, pp. 259-261, 2013.

[8] Abrzhina, L.L. \& Magaril, E.R., Assessment of environmental-economic effectiveness of multifunctional fuel additives. WIT Transactions on Ecology and The Environment, 198, WIT Press: UK, pp. 287-294, 2015. 